\title{
Correlates of Undiagnosed Hypertension Among Chinese and Korean American Immigrants
}

\author{
Brittany N. Morey ${ }^{1}\left[\right.$ Connie Valencia ${ }^{1} \cdot$ Sunmin Lee $^{2}$
}

Accepted: 15 January 2022 / Published online: 1 February 2022

(c) The Author(s), under exclusive licence to Springer Science+Business Media, LLC, part of Springer Nature 2022

\begin{abstract}
Asian Americans are more likely to be unaware that they have hypertension compared to non-Hispanic white Americans, despite having higher risk of hypertension at lower body-mass indices. Furthermore, immigrants are more likely than their United States (U.S.)-born counterparts to have undiagnosed hypertension, placing them at greater risk of subsequent morbidity and mortality. This study examines the social determinants of undiagnosed hypertension among Asian American immigrants. Using a study of foreign-born Chinese and Korean Americans between the ages of 50-75 years-old recruited from physicians' clinics in the Baltimore-Washington DC Metropolitan Area $(n=355)$, we used blood pressure readings measured by trained staff members, self-reported diagnosis by a medical professional, and self-reported hypertension medication use to determine hypertension status - whether patients were non-hypertensive, had diagnosed hypertension, or had undiagnosed hypertension. Using multinomial logistic regression, we examined how demographic, socioeconomic, and immigration-related factors were associated with hypertension status. Results indicated that older age, male gender, Korean subgroup, and marital status were associated with having diagnosed hypertension compared to being non-hypertensive. Lack of health insurance was the strongest predictor of having undiagnosed hypertension compared to being non-hypertensive. Acculturation variables had no strong associations with hypertension status. We then explored correlates of health insurance status for Chinese and Korean American immigrants. Those without health insurance were more likely to have lower income and to be not currently employed. Our findings point to the importance of increasing health insurance access for Asian American immigrant groups to ensure that hypertension is not left undiagnosed and untreated.
\end{abstract}

Keywords Undiagnosed hypertension · Asian Americans $\cdot$ Immigrants $\cdot$ Health insurance $\cdot$ Socioeconomic status

\section{Introduction}

An estimated 11 million people in the United States (U.S.) have hypertension, but they remain undiagnosed $[1,2]$. When people are unaware that they have high blood pressure and they do not receive the treatment to control it, this can lead to severe disease complications such as heart attack, stroke, metabolic syndrome, and dementia that could have been prevented [3]. Public health efforts have focused on

Brittany N. Morey

brittany.morey@uci.edu

1 Department of Health, Society, \& Behavior, Program in Public Health, University of California, Irvine, $653 \mathrm{E}$. Peltason Dr., Anteater Instruction and Research Building (AIRB) 2022, Irvine, CA 92697-3957, USA

2 Department of Medicine, School of Medicine, University of California, Irvine, Irvine, CA, USA decreasing the number of people with undiagnosed hypertension in order treat it and prevent morbidity and mortality. However, far fewer efforts have been made to identify undiagnosed hypertension among immigrants living in the U.S., even though evidence indicates that immigrants are more likely to have undiagnosed hypertension than their U.S.-born counterparts [4]. Approximately 70\% of Asian American adults are immigrants [5]. Research indicates that Asian Americans overall have high rates of undiagnosed hypertension compared to the general population. For example, one study using data from the National Health and Nutrition Examination Survey (NHANES) found that Asian Americans were at $41 \%$ greater odds of having undiagnosed hypertension compared to white Americans [6]. Another community-based study found that hypertension prevalence determined by direct blood pressure measurement among Chinese, Korean, and Vietnamese Americans was 27.5\%, which was higher than the NHANES estimate of $24.9 \%$ 
among Asian Americans based solely on self-reported diagnosis by a medical professional [7]. Together, these findings indicate that for reasons largely unknown, Asian Americans are more likely to be unaware that they have hypertension and are therefore at increased risk of untreated hypertension leading to more severe morbidity and mortality.

One reason that hypertension has been an overlooked problem among Asian Americans may be the common, but incorrect perception that Asians are not at high risk for cardiovascular disease. Asian American men and women on average have lower body mass indices (BMIs) and lower prevalence of overweight and obesity compared to other racial/ethnic groups in the U.S. [8]. However, research finds that Asian American populations are at greater risk of developing hypertension at lower BMIs than other racial/ethnic groups [9-11]. Using data from the California Behavioral Risk Factor Survey, Wong et a. (2013) found that although Asians had the lowest BMIs on average, they were significantly more likely to have hypertension for every one-unit increase in BMI compared to a similar one-unit increase in BMI among white, Black, and Hispanic individuals [9]. Research in New York City found that after adjusting for age, sex, and BMI, Asian adults had twice the odds of hypertension as non-Hispanic white adults [12]. We can also gain some understanding of potential risk for hypertension among Asian Americans from studies conducted in Asia. One study comparing a sample of Chinese people living in China to white and Black populations in the U.S. found that among young and middle-aged adults, the association between BMI and incidence of hypertension was stronger among Chinese than American populations [13]. Another study using the Korea National Health and Nutrition Examination Survey found that Koreans may be at high risk of hypertension even when they are not obese, due to higher waist circumference and percentage body fat measurements that were present at normal BMIs [14].

The burden of hypertension at lower BMIs presents a problem for appropriately diagnosing Asian Americans, and likely contributes to disparities for more severe health outcomes and mortality observed among Asian American populations. Asian Americans experience higher rates of hemorrhagic stroke compared to white Americans, and hypertensive disease-related deaths account for a higher percentage of all deaths among Asian Americans when compared to white Americans [15]. Heart attack and stroke, both closely related to undiagnosed and untreated hypertension, remain the second and third leading causes of death among Asian populations in the U.S. [16, 17].

These observations led us to inquire: what social determinants of health are leading to undiagnosed hypertension among Asian American immigrants? Furthermore, are there issues related to the immigrant experience that contribute to undiagnosed hypertension among foreign-born Asian
Americans? Since some Asian populations including Koreans develop hypertension at younger ages than average in the U.S. [18], it is possible that those with undiagnosed hypertension are younger in age. Differences in hypertension status may exist by gender or country of origin [7]. Socioeconomic status likely plays a major role in undiagnosed hypertension among Asian Americans [19]. Although Asian Americans as an aggregate group are more highly educated and earning higher incomes on average, there is great variation in socioeconomic status among Asian subpopulations, with the needs of the many low-income and low-education Asian Americans often being overlooked [5]. Employment may play a role as well. While most foreign-born Asian Americans work, they are more likely than U.S.-born Asian Americans to work in blue-collar jobs or as service workers, often in small businesses or as small business ownersoccupations that interfere with receiving routine medical care and that often do not offer health insurance [20,21].

This also leads us to expect that health insurance likely plays a role in having undiagnosed hypertension [22, 23]. In addition to potentially working in jobs that do not offer health insurance, there are barriers to accessing health insurance among those who immigrated [21]. Under federal law, all legal immigrants must undergo a minimum five-year waiting period in the U.S. before they can qualify for public benefits such as Medicaid and Medicare [24, 25]. Many who do eventually qualify may not use these public health insurance options due to stigma and not wanting to be considered a public charge, which in their view may jeopardize their application to become U.S. citizens [26-28]. Undocumented Asian immigrants cannot access Medicaid and Medicare benefits at all. Therefore, health insurance is a social determinant of health that may impact undiagnosed hypertension among Asian American immigrants.

Lastly, Asian American immigrants experience stress related to navigating life in the U.S., including the process of acculturation and limited English proficiency for some [29]. Acculturation is defined here as the "process by which individuals adapt to a new living environment and potentially adopt the norms, values, and practices of their new host society" [30]. Asian American immigrants who experience more difficulty and stress navigating U.S. society and with speaking English may also experience barriers to receiving the healthcare they need, over and above health insurance coverage, contributing to undiagnosed hypertension $[29,31]$. Acculturation also depends on the age at which people immigrate to the U.S. It is possible that those who immigrated when they were older may have more difficulty navigating the complex U.S. healthcare system, leading to more undiagnosed hypertension [11,32].

This study examined in-depth how social determinants of health are associated with diagnosed and undiagnosed hypertension in a sample of Chinese and Korean American 
immigrants. Specifically, we tested the associations between demographic characteristics, socioeconomic status, health insurance, and acculturation factors with hypertension status-whether people were non-hypertensive, had diagnosed hypertension, or had undiagnosed hypertension. After finding that health insurance seems to play a major role in undiagnosed hypertension, we further explored the sociodemographic factors associated with health insurance status among Chinese and Korean American immigrants. By studying these associations, we can better inform efforts to improve the diagnosis and treatment of hypertension to prevent more severe morbidity and mortality among Asian American subpopulations.

\section{Methods}

\section{Data Source}

This study examines baseline data from a randomized controlled trial. The Screening to Prevent Colorectal Cancer (STOP CRC) Among Chinese and Korean Americans Study baseline data collection was conducted between August 2018 and June 2020 . The study purpose was to improve colorectal cancer screening among 200 Chinese and 200 Korean Americans $(n=400)$ between the ages of 50-75 living in the Baltimore-Washington DC Metropolitan Area. Participants were recruited from primary care physicians' clinics in Maryland and Northern Virginia. After participants provided written informed consent, they were asked to complete a survey either in person or via phone in their preferred language (Mandarin, Korean, or English). A majority of participants $(92 \%, \mathrm{n}=355)$ completed their questionnaire in person and also provided blood samples, anthropometric measurements, and blood pressure measurements to trained research staff members. However, due to COVID-19, from March 2020 through June 2020, $8 \%(n=45)$ of study participants completed their questionnaire via phone with the assistance of a researcher and did not complete in-person assessments, including blood pressure measurements. As a result, 45 participants without blood pressure measurement were excluded from the current analysis. The study was approved by the Institutional Review Boards of the University of Maryland, College Park, and the University of California, Irvine.

\section{Dependent Variable}

The dependent variable was hypertension status. Study participants provided three blood pressure measurements obtained by trained staff using the Omron blood pressure monitor (Model BP710). We calculated systolic and diastolic blood pressure by taking the average of the second and third measurements according to recommended practice
$[7,33]$. Blood pressure measurements were used to indicate hypertension using the guidelines recommended by the Joint National Committee on Prevention, Detection, Evaluation and Treatment of High Blood Pressure (hypertension is present when systolic blood pressure is greater than or equal to $140 \mathrm{~mm} \mathrm{Hg}$ or when diastolic blood pressure is greater than or equal to $90 \mathrm{~mm} \mathrm{Hg}$ ) [34]. In the survey, participants were additionally asked if they had been told by a doctor or other medical professional in the past year or ever that they had high blood pressure, and if they were on medication for hypertension. Hypertension status was categorized as follows based on blood pressure measurements and self-report: (1) no hypertension, (2) diagnosed hypertension, and (3) undiagnosed hypertension. "No hypertension" was defined as a person having systolic blood pressure less than $140 \mathrm{~mm}$ $\mathrm{Hg}$ and diastolic blood pressure less than $90 \mathrm{~mm} \mathrm{Hg}$ and having answered "no" to both having been diagnosed with hypertension and being on hypertension medications. "Diagnosed hypertension" was defined as anyone who reported "yes" to having been diagnosed with hypertension or being on hypertension medications, regardless of blood pressure reading, as hypertensive medications and treatment may lower blood pressure readings to a normal range. "Undiagnosed hypertension" was defined as a person having a systolic blood pressure greater than or equal to $140 \mathrm{~mm} \mathrm{Hg}$ and/or a diastolic blood pressure greater than or equal to $90 \mathrm{~mm} \mathrm{Hg}$, and who also answered "no" to both having been diagnosed with hypertension and being on hypertension medications.

\section{Independent Variables}

Independent variables included the following demographic factors: age (continuous), gender (male or female), Asian subgroup (Korean or Chinese), and marital status (married/cohabitating or not currently married). Socioeconomic variables included: education (less than or equal to high school graduate, some college/college graduate, or graduate/professional school), household income (less than $\$ 20,000, \$ 20,000-\$ 59,999, \$ 60,000-\$ 99,000$, or $\$ 100,000$ or more) and employment status (full time, part time, or not employed). We also included health insurance (private insurance, Medicare/Medicaid, or no health insurance).

Lastly, we considered the following acculturation variables: English speaking proficiency, acculturative stress, and age of immigration. English speaking proficiency was determined by asking respondents, "How well do you speak English?" and responses were categorized as "poorly/not at all," "so-so," or "fluently/well." Acculturative stress was defined as stressors associated with the experience of being an immigrant and racial/ethnic minority in a cultural context different from that of one's country of origin [35-37]. Acculturative stress was measured using a 9-item scale adopted 
from the National Latino and Asian American Longitudinal Survey [38-40]. Questions included: "do you feel that living out of your country has limited your contact with family or friends?" "do you find it hard interacting with others because of difficulties you have with the English language?" and "do you avoid seeking health services due to fear of immigration officials?" Positive "yes" answers were coded as 1, while "no" answers were coded as 0. Acculturative stress was calculated as the sum of the 9 items to create a total score ranging from 0 to 9 , with higher scores indicating greater acculturative stress. Age of immigration was calculated by subtracting participants' reported year of birth from the year of immigration.

\section{Analyses}

Data analyses were conducted in Stata version 16 [41]. First, we conducted descriptive analysis of the sample. We calculated descriptive statistics for the total sample and then stratified by hypertension status. We used chi-square tests (for categorical variables) and analysis of variance (ANOVA) (for continues variables) to calculate the $\mathrm{p}$-values for differences in the independent variables across the 3 hypertension statuses. We then calculated relative risk ratios (RRRs) using multinomial logistic regression to examine the associations between the independent variables and hypertension status. We used "no hypertension" as the referent dependent group outcome. The first regression model included demographic variables. The second model added socioeconomic variables and health insurance. The third model added acculturation variables. Last, we conducted an additional multinomial logistic regression analysis to examine associations between independent variables and health insurance status, using private health insurance as the referent group outcome. We calculated how each independent variable was associated with health insurance status, unadjusted for any other variables. We then provided a fully adjusted model with all independent variables included.

\section{Results}

\section{Descriptive Statistics}

Table 1 provides descriptive statistics for the total sample, then stratified by hypertension status. Out of 355 study participants, $46.5 \%$ had no hypertension, while the majority (53.5\%) had either diagnosed or undiagnosed hypertension. In the total sample, $38.9 \%(\mathrm{n}=138)$ had diagnosed hypertension while $14.7 \%(\mathrm{n}=52)$ had undiagnosed hypertension. Average age among study participants was 58 . Of participants, $53 \%$ were identified as female and $56 \%$ identified as Korean. A majority of participants were married, completed at least some college, worked full time, and had private health insurance.

There were differences in the sample by hypertension status. On average, participants with diagnosed hypertension were older (61 years) in comparison to those with no hypertension (57 years) and those with undiagnosed hypertension (59 years). Men made up a greater proportion of those with undiagnosed hypertension $(67.3 \%)$ and diagnosed hypertension (54.4\%) compared to those with no hypertension (33.9\%). Korean Americans, who made up 56.3\% of the total sample, also made up a larger percentage of those who were undiagnosed $(61.5 \%)$ and diagnosed with hypertension $(69.6 \%)$. The percentage of people who were married/ cohabitating was highest among those with undiagnosed hypertension (94.2\%) and was higher than average among those with diagnosed hypertension (88.4\%). Educational attainment was highest among those with no hypertension, followed by those with undiagnosed hypertension, and then those with diagnosed hypertension. Income was similar comparing those with no hypertension and those with undiagnosed hypertension but was lower among those with diagnosed hypertension. Health insurance differed across the three hypertension status groups. While those with no hypertension had the highest rate of private insurance, those with diagnosed hypertension had the highest rate of Medicare/ Medicaid insurance. Those with undiagnosed hypertension had the highest rate of uninsurance compared to those with no hypertension and those with diagnosed hypertension, with over $30 \%$ of participants in that group reporting having no health insurance. The three hypertension status groups were similar on measures of acculturation (English speaking proficiency, acculturative stress, and age of immigration).

\section{Associations with Hypertension Status}

Results of the multinomial logistic regression examining hypertension status are in Table 2. The dependent reference group was participants with no hypertension. In Model 1, older age was significantly associated with higher risk of being diagnosed with hypertension (RRR $1.09,95 \%$ CI $1.05-1.14, \mathrm{p}<0.01)$. However, age was not highly associated with undiagnosed hypertension compared to no hypertension (RRR 1.04, 95\% CI 0.99-1.11, p > 0.1). Being female in comparison to male (RRR 0.45 , 95\% CI 0.27-0.75, $\mathrm{p}<0.01$ ), Chinese compared to Korean (RRR 0.44, 95\% CI 0.26-0.73, p < 0.01), and unmarried compared to married/ cohabitating (RRR 0.47, 95\% CI 0.23-0.93, p < 0.05) were all associated with lower risk of being diagnosed with hypertension, compared to those with no hypertension. Similarly, being female in comparison to male (RRR $0.27,95 \% \mathrm{CI}$ $0.13-0.53, \mathrm{p}<0.01)$ and being unmarried compared to mar$\mathrm{ried} /$ cohabitating (RRR $0.27,95 \%$ CI $0.08-0.96, \mathrm{p}<0.05$ ) 
Table 1 Descriptive statistics $(\mathrm{n}=355)$

\begin{tabular}{|c|c|c|c|c|c|}
\hline \multirow[t]{2}{*}{ Variables } & \multicolumn{4}{|l|}{ Freq. $(\%)$} & \multirow[t]{2}{*}{ p-value } \\
\hline & $\begin{array}{l}\text { Total sample } \\
\mathrm{n}=355(100 \%)\end{array}$ & $\begin{array}{l}\text { No hypertension } \\
\mathrm{n}=165(46.5 \%)\end{array}$ & $\begin{array}{l}\text { Diagnosed hypertension } \\
\mathrm{n}=138(38.9 \%)\end{array}$ & $\begin{array}{l}\text { Undiagnosed hypertension } \\
\mathrm{n}=52(14.6 \%)\end{array}$ & \\
\hline Age (Mean, SD) & $58.48(6.38)$ & $56.63(6.03)$ & $60.61(6.30)$ & $58.67(5.96)$ & 0.000 \\
\hline \multicolumn{6}{|l|}{ Gender } \\
\hline Male & $166(46.8)$ & $56(33.9)$ & $75(54.4)$ & $35(67.3)$ & 0.000 \\
\hline Female & $189(53.2)$ & $109(66.1)$ & $63(45.7)$ & $17(32.7)$ & 0.000 \\
\hline \multicolumn{6}{|l|}{ Asian Subgroup } \\
\hline Korean & $200(56.3)$ & $72(43.6)$ & $96(69.6)$ & $32(61.5)$ & \multirow[t]{2}{*}{0.000} \\
\hline Chinese & $155(43.7)$ & $93(56.4)$ & $42(30.4)$ & $20(38.5)$ & \\
\hline \multicolumn{6}{|l|}{ Marital status } \\
\hline Married/Cohabit & $304(85.6)$ & $133(80.6)$ & $122(88.4)$ & $49(94.2)$ & \multirow[t]{2}{*}{0.025} \\
\hline Not currently married & $51(14.4)$ & $32(19.4)$ & $16(11.6)$ & $3(5.8)$ & \\
\hline \multicolumn{6}{|l|}{ Education } \\
\hline$\leq$ High school graduate & $122(34.4)$ & $47(28.5)$ & $61(44.2)$ & $14(26.9)$ & \multirow[t]{3}{*}{0.026} \\
\hline Some college/college graduate & $152(42.8)$ & $73(44.2)$ & $54(39.1)$ & $25(48.1)$ & \\
\hline Graduate/professional school & $81(22.8)$ & $45(27.3)$ & $23(16.7)$ & $13(25.0)$ & \\
\hline \multicolumn{6}{|l|}{ Household income } \\
\hline$<\$ 20 \mathrm{~K}$ & $56(15.8)$ & $22(13.3)$ & $28(20.3)$ & $6(11.5)$ & \multirow[t]{4}{*}{0.074} \\
\hline$\$ 20-\$ 59 \mathrm{~K}$ & $134(37.8)$ & $60(36.4)$ & $55(39.9)$ & $19(36.5)$ & \\
\hline$\$ 60-99 \mathrm{~K}$ & $73(20.6)$ & $31(18.8)$ & $32(23.2)$ & $10(19.2)$ & \\
\hline$\geq \$ 100 \mathrm{~K}$ & $92(25.9)$ & $52(31.5)$ & $23(16.7)$ & $17(32.7)$ & \\
\hline \multicolumn{6}{|l|}{ Employment status } \\
\hline Full time & $205(57.8)$ & $102(61.8)$ & $68(49.3)$ & $35(67.3)$ & \multirow[t]{3}{*}{0.107} \\
\hline Part time & $79(22.3)$ & $34(20.6)$ & $35(25.4)$ & $10(19.2)$ & \\
\hline Not employed & $71(20.0)$ & $29(17.6)$ & $35(25.4)$ & $7(13.5)$ & \\
\hline \multicolumn{6}{|l|}{ Health insurance } \\
\hline Private insurance & $209(58.9)$ & $116(70.3)$ & $67(48.6)$ & $26(50.0)$ & \multirow[t]{3}{*}{0.001} \\
\hline Medicare/Medicaid & $70(19.7)$ & $23(13.9)$ & $37(26.8)$ & $10(19.2)$ & \\
\hline No health insurance & $76(21.4)$ & $26(15.8)$ & $34(24.6)$ & $16(30.8)$ & \\
\hline \multicolumn{6}{|l|}{ English speaking proficiency } \\
\hline Poorly/not at all & $141(39.7)$ & $57(34.6)$ & $62(44.9)$ & $22(42.3)$ & \multirow[t]{3}{*}{0.290} \\
\hline So-so & $137(38.6)$ & $65(39.4)$ & $52(37.7)$ & $20(38.5)$ & \\
\hline Fluent/well & $77(21.7)$ & $43(26.1)$ & $24(17.4)$ & $10(19.2)$ & \\
\hline Acculturative Stress (mean, SD) & $1.61(1.54)$ & $1.55(1.52)$ & $1.61(1.50)$ & $1.83(1.75)$ & 0.519 \\
\hline Age of Immigration (mean, SD) & $35.33(10.81)$ & $34.61(10.37)$ & $35.72(11.86)$ & $36.54(9.14)$ & 0.464 \\
\hline
\end{tabular}

$S D$ standard deviation. Not all percentages may add up to $100 \%$ due to rounding

were associated with lower risk of having undiagnosed hypertension, compared to those with no hypertension.

In Model 2, participants with higher educational attainment had lower risk of diagnosed hypertension compared to no hypertension. None of the other socioeconomic variables were associated strongly with diagnosed hypertension. Health insurance status was strongly associated with undiagnosed hypertension compared to having no hypertension. Those without health insurance had 4.22 times the risk of undiagnosed hypertension on average compared to those with private health insurance (RRR 4.22, 95\% CI
$1.71-10.40, \mathrm{p}<0.01)$. None of the other socioeconomic variables were strongly associated with undiagnosed hypertension.

In Model 3, none of the added acculturation variables were strongly associated with hypertension status. In this final model, the variables most strongly associated with diagnosed hypertension were older age, male gender compared to female gender, Korean compared to Chinese subgroup, and being married compared to being unmarried. The variables most strongly associated with undiagnosed hypertension were male gender compared to female gender, being 
Table 2 Multinomial logistic regression of diagnosed hypertension and undiagnosed hypertension (reference group $=$ no hypertension) on covariates $(\mathrm{n}=355)$

\begin{tabular}{|c|c|c|c|c|c|c|}
\hline \multirow{3}{*}{$\begin{array}{l}\text { Dependent reference } \\
\text { group = No Hyper- } \\
\text { tension }\end{array}$} & \multicolumn{3}{|c|}{ Diagnosed hypertension } & \multicolumn{3}{|c|}{ Undiagnosed hypertension } \\
\hline & \multicolumn{3}{|c|}{ Relative risk ratio $(95 \% \mathrm{CI})$} & \multicolumn{3}{|c|}{ Relative risk ratio $(95 \% \mathrm{CI})$} \\
\hline & Model 1 & Model 2 & Model 3 & Model 1 & Model 2 & Model 3 \\
\hline Age & $1.09(1.05-1.14)^{* *}$ & $1.08(1.03-1.14)^{* *}$ & $1.10(1.04-1.16)^{* *}$ & $1.04(0.99-1.11)$ & $1.05(0.98-1.12)$ & $1.03(0.95-1.11)$ \\
\hline \multicolumn{7}{|l|}{ Gender } \\
\hline Male & 1.00 & 1.00 & 1.00 & 1.00 & 1.00 & 1.00 \\
\hline Female & $0.45(0.27-0.75)^{* *}$ & $0.36(0.20-0.63)^{* *}$ & $0.36(0.20-0.64)^{* *}$ & $0.27(0.13-0.53)^{* *}$ & $\begin{array}{l}0.29(0.14- \\
0.60)^{* *}\end{array}$ & $0.29(0.14-0.60)^{* *}$ \\
\hline \multicolumn{7}{|l|}{ Asian subgroup } \\
\hline Korean & 1.00 & 1.00 & 1.00 & 1.00 & 1.00 & 1.00 \\
\hline Chinese & $0.44(0.26-0.73)^{* *}$ & $0.42(0.24-0.75)^{* *}$ & $0.44(0.24-0.80)^{* *}$ & $0.52(0.26-1.03)^{\dagger}$ & $0.56(0.27-1.16)$ & $0.52(0.23-1.15)$ \\
\hline \multicolumn{7}{|l|}{ Marital status } \\
\hline Married/cohabit & 1.00 & 1.00 & 1.00 & 1.00 & 1.00 & 1.00 \\
\hline $\begin{array}{l}\text { Not currently } \\
\text { married }\end{array}$ & $0.47(0.23-0.93)^{*}$ & $0.46(0.22-0.94)^{*}$ & $0.46(0.22-0.93)^{*}$ & $0.27(0.08-0.96)^{*}$ & $0.24(0.07-0.86)^{*}$ & $0.22(0.06-0.84)^{*}$ \\
\hline \multicolumn{7}{|l|}{ Education } \\
\hline $\begin{array}{l}\leq \text { High school } \\
\text { graduate }\end{array}$ & & 1.00 & 1.00 & & 1.00 & 1.00 \\
\hline $\begin{array}{l}\text { Some college/ } \\
\text { college graduate }\end{array}$ & & $0.53(0.29-0.97)^{*}$ & $0.53(0.27-1.05)^{\dagger}$ & & $1.01(0.44-2.34)$ & $1.41(0.56-3.58)$ \\
\hline $\begin{array}{l}\text { Graduate/ } \\
\text { professional school }\end{array}$ & & $0.68(0.30-1.57)$ & $0.69(0.25-1.92)$ & & $0.93(0.31-2.78)$ & $1.54(0.41-5.84)$ \\
\hline \multicolumn{7}{|l|}{ Income } \\
\hline$<\$ 20 \mathrm{~K}$ & & 1.00 & 1.00 & & 1.00 & 1.00 \\
\hline$\$ 20-\$ 59 \mathrm{~K}$ & & $1.30(0.56-3.06)$ & $1.31(0.56-3.07)$ & & $1.54(0.46-5.23)$ & $1.50(0.45-4.99)$ \\
\hline$\$ 60-99 \mathrm{~K}$ & & $1.51(0.59-3.89)$ & $1.51(0.59-3.84)$ & & $1.19(0.31-4.61)$ & $1.25(0.33-4.82)$ \\
\hline$\geq \$ 100 \mathrm{~K}$ & & $1.02(0.36-2.91)$ & $0.94(0.33-2.71)$ & & $2.42(0.54-10.90)$ & $3.41(0.76-15.12)$ \\
\hline \multicolumn{7}{|l|}{ Employment } \\
\hline Full time & & 1.00 & 1.00 & & 1.00 & 1.00 \\
\hline Part time & & $1.60(0.80-3.22)$ & $1.65(0.81-3.35)$ & & $1.03(0.37-2.85)$ & $1.00(0.37-2.66)$ \\
\hline Not employed & & $1.51(0.71-3.23)$ & $1.63(0.75-3.53)$ & & $0.70(0.24-2.06)$ & $0.54(0.17-1.68)$ \\
\hline \multicolumn{7}{|l|}{ Health insurance } \\
\hline Private & & 1.00 & 1.00 & & 1.00 & 1.00 \\
\hline Medicare/Medicaid & & $0.95(0.40-2.24)$ & $0.87(0.37-2.08)$ & & $1.70(0.55-5.29)$ & $2.19(0.66-7.25)$ \\
\hline None & & $1.82(0.92-3.58)^{\dagger}$ & $1.85(0.94-3.65)^{\dagger}$ & & $\begin{array}{c}4.22(1.71- \\
10.40)^{* *}\end{array}$ & $\begin{array}{c}4.29(1.77- \\
10.40)^{* *}\end{array}$ \\
\hline \multicolumn{7}{|c|}{ English speaking proficiency } \\
\hline Poorly/not at all & & & 1.00 & & & 1.00 \\
\hline So-so & & & $0.86(0.40-1.83)$ & & & $0.63(0.22-1.80)$ \\
\hline Fluent/well & & & $1.00(0.35-2.85)$ & & & $0.38(0.07-1.94)$ \\
\hline Acculturative stress & & & $0.95(0.79-1.15)$ & & & $1.05(0.81-1.35)$ \\
\hline Age of immigration & & & $0.98(0.95-1.02)$ & & & $1.01(0.97-1.06)$ \\
\hline
\end{tabular}

CI confidence interval

${ }^{\dagger} \mathrm{p}<0.1, * \mathrm{p}<0.05, * * \mathrm{p}<0.01$ 
married compared to being unmarried, and having no health insurance compared to having private insurance.

\section{Associations with Health Insurance Status}

Results of multinomial logistic regression models of health insurance status are shown in Table 3. In the unadjusted model, participants with Medicare/Medicaid are more likely to be older and Korean compared to those with private insurance. Socioeconomic factors associated with having Medicare/Medicaid compared to private insurance in the unadjusted model were lower education, lower income, and not having full-time employment. Regarding acculturation factors, participants who spoke English "poorly/not at all" and those who immigrated at older age were more likely to have Medicare/Medicaid than those who had better English proficiency and immigrated at younger ages in the unadjusted model. In the fully adjusted model, the variables most strongly associated with having Medicare/Medical compared to having private insurance were older age, male gender, Korean identity, lower income, and not being currently employed. After fully adjusting for other covariates, age of immigration and English speaking proficiency were no longer significantly associated with having Medicare/Medicaid.

In the unadjusted model, participants with no health insurance compared to having private insurance were more likely

Table 3 Multinomial logistic regression of health insurance on covariates, unadjusted and adjusted models. $(\mathrm{n}=355)$

\begin{tabular}{|c|c|c|c|c|}
\hline \multirow{3}{*}{$\begin{array}{l}\text { Dependent reference group }=\text { Private } \\
\text { Health Insurance }\end{array}$} & \multicolumn{2}{|l|}{ Medicare/Medicaid } & \multicolumn{2}{|l|}{ No health insurance } \\
\hline & Unadjusted model & Adjusted model & Unadjusted model & Adjusted model \\
\hline & $\operatorname{RRR}(95 \% \mathrm{CI})$ & $\operatorname{RRR}(95 \% \mathrm{CI})$ & $\operatorname{RRR}(95 \% \mathrm{CI})$ & $\operatorname{RRR}(95 \% \mathrm{CI})$ \\
\hline Age & $1.27(1.18-1.37)^{* *}$ & $1.23(1.13-1.33)^{* *}$ & $1.07(1.03-1.12)^{* *}$ & $1.02(0.96-1.08)$ \\
\hline \multicolumn{5}{|l|}{ Gender } \\
\hline Male & 1.00 & 1.00 & 1.00 & 1.00 \\
\hline Female & $0.64(0.37-1.10)$ & $0.29(0.13-0.67)^{* *}$ & $0.99(0.58-1.68)$ & $0.70(0.38-1.31)$ \\
\hline \multicolumn{5}{|l|}{ Asian subgroup } \\
\hline Korean & 1.00 & 1.00 & 1.00 & 1.00 \\
\hline Chinese & $0.23(0.12-0.44)^{* *}$ & $0.23(0.07-0.83)^{*}$ & $0.94(0.56-1.59)$ & $1.03(0.54-2.00)$ \\
\hline \multicolumn{5}{|l|}{ Marital status } \\
\hline Married/cohabit & 1.00 & 1.00 & 1.00 & 1.00 \\
\hline Not currently married & $1.84(0.90-3.78)^{\dagger}$ & $2.31(0.81-6.58)$ & $1.38(0.65-2.91)$ & $1.60(0.68-3.73)$ \\
\hline \multicolumn{5}{|l|}{ Education } \\
\hline$\leq$ High school graduate & 1.00 & 1.00 & 1.00 & 1.00 \\
\hline Some college/college graduate & $0.36(0.19-0.65)^{* *}$ & $0.38(0.14-1.04)^{\dagger}$ & $0.67(0.37-1.22)$ & $0.70(0.38-1.31)$ \\
\hline Graduate/professional school & $0.11(0.04-0.29)^{* *}$ & $0.28(0.06-1.44)$ & $0.38(0.18-0.80)^{*}$ & $1.34(0.46-3.93)$ \\
\hline \multicolumn{5}{|l|}{ Income } \\
\hline$<\$ 20 \mathrm{~K}$ & 1.00 & 1.00 & 1.00 & 1.00 \\
\hline$\$ 20-\$ 59 \mathrm{~K}$ & $0.13(0.06-0.30)^{* *}$ & $0.22(0.07-0.68)^{* *}$ & $0.33(0.14-0.79)^{*}$ & $0.57(0.23-1.41)$ \\
\hline$\$ 60-99 \mathrm{~K}$ & $0.11(0.04-0.30)^{* *}$ & $0.19(0.05-0.70)^{*}$ & $0.69(0.27-1.72)$ & $1.45(0.52-4.04)$ \\
\hline$\geq \$ 100 \mathrm{~K}$ & $0.02(0.01-0.06)^{* *}$ & $0.04(0.00-0.20)^{* *}$ & $0.04(0.01-0.14)^{* *}$ & $0.07(0.02-0.26)^{* *}$ \\
\hline \multicolumn{5}{|l|}{ Employment } \\
\hline Full time & 1.00 & 1.00 & 1.00 & 1.00 \\
\hline Part time & $3.04(1.53-6.06)^{* *}$ & $2.13(0.78-5.83)$ & $1.98(1.02-3.83)^{*}$ & $1.56(0.74-3.30)$ \\
\hline Not employed & $6.88(3.38-14.00)^{* *}$ & $6.02(2.11-17.10)^{* *}$ & $3.99(2.00-7.97)^{* *}$ & $2.84(1.19-6.79)^{*}$ \\
\hline \multicolumn{5}{|l|}{ English speaking proficiency } \\
\hline Poorly/not at all & 1.00 & 1.00 & 1.00 & 1.00 \\
\hline So-so & $0.38(0.21-0.72)^{* *}$ & $0.85(0.29-2.53)$ & $0.46(0.26-0.82)^{* *}$ & $0.81(0.39-1.78)$ \\
\hline Fluent/well & $0.31(0.14-0.66)^{* *}$ & $2.81(0.53-14.80)$ & $0.21(0.09-0.48)^{* *}$ & $0.99(0.27-3.58)$ \\
\hline Acculturative stress & $1.06(0.89-1.27)$ & $0.96(0.73-1.25)$ & $1.17(0.99-1.37)^{\dagger}$ & $1.05(0.87-1.28)$ \\
\hline Age of immigration & $1.03(1.00-1.06)^{*}$ & $0.97(0.93-1.01)$ & $1.06(1.03-1.08)^{* *}$ & $1.02(0.99-1.06)$ \\
\hline
\end{tabular}

Unadjusted model examines the association between each independent variable and health insurance, not accounting for any other variables. Adjusted model accounts for all other independent variables

$R R R$ relative risk ratio, $C I$ confidence interval

${ }^{\dagger} \mathrm{p}<0.1,{ }^{*} \mathrm{p}<0.05, * * \mathrm{p}<0.01$ 
to be older, lower educational attainment, lower income, and to be working part-time or not currently employed. In addition, lower English proficiency and older age of immigration were significantly correlated with being uninsured in the unadjusted model. In the fully adjusted model, the variables most strongly associated with having no health insurance were lower income (less than $\$ 20,000$ versus over $\$ 100,000)$ (RRR 0.07, 95\% CI 0.02-0.26, p <0.01) and not being currently employed (compared to working full-time) (RRR 2.84, 95\% CI 1.19-6.79, p < 0.05). English proficiency and age of immigration were not significantly associated with having no health insurance in the fully adjusted model.

\section{Discussion}

In this paper, we sought to examine undiagnosed hypertension among Chinese and Korean Americans. Specifically, we determined which sociodemographic and acculturation factors were associated with someone being either diagnosed or undiagnosed for hypertension. Notably, our study found that among participants ages 50 to 75 years, $53.5 \%$ had either diagnosed or undiagnosed hypertension. This is compared to data from another study that found among Asian Americans in Los Angeles County, 32.9\% ages 50-64 and 59.6\% ages $65+$ had hypertension [42]. Although the prevalence of hypertension in our sample seems higher than a previous age-adjusted estimate of hypertension of $27.5 \%$ among Chinese, Korean, and Vietnamese adult participants 18 years-old and older in the Washington-Baltimore Metropolitan Area, the prevalence of hypertension in our study seems similar to other research on middle-aged and older Asian Americans $[7,43]$.

What is most concerning in our study is that $14.6 \%$ of participants were found to be undiagnosed with hypertension. In other words, among those with hypertension, $27.4 \%$ (52 out of 190) had never been told by a medical professional that they had hypertension, despite having high blood pressure. These numbers are higher than the $12.9 \%$ found to have undiagnosed hypertension in a racially diverse sample of community clinics across multiple states [44]. Other studies have found that of adults 18 years-old and older, Asian Americans have the highest rates of undiagnosed hypertension compared to non-Hispanic white, Black, and Hispanic Americans [6, 45]. Our estimate of $27.4 \%$ being unaware of their hypertension among those with high blood pressure is slightly higher than a national estimate of $24.7 \%$ among Asian Americans calculated using data from the Centers for Disease Control and Prevention [45]. The high rate of undiagnosed hypertension in our study of Asian Americans is especially troubling, considering that participants were recruited from primary care physicians' offices and therefore have some access to primary health care. Undiagnosed hypertension is likely even more prevalent in the Asian American population who do not go to primary care offices.

This is one of the few studies to assess sociodemographic correlates of diagnosed and undiagnosed hypertension among Asian Americans. Among study participants, those with diagnosed and undiagnosed hypertension were more likely to be older, male, Korean, married, have lower educational attainment, and have no health insurance. Regression analyses revealed the most important factors related to diagnosed hypertension. Compared to participants without hypertension, those with diagnosed hypertension were more likely to be older, male, Korean, and married. These findings coincide with other studies finding that older Asian Americans and men are more likely to have hypertension [6, 42, 46]. Further, studies have found Korean Americans have higher prevalence of hypertension than Chinese Americans $[7,47]$. Our finding that being married/cohabitating was associated with higher likelihood of diagnosed hypertension contradicts prior studies of this topic [48, 49]. More research is needed to clarify this association among Asian Americans and how it might differ from other populations. In our study, acculturation factors-English speaking proficiency, acculturative stress, and age of immigration-were not associated with having diagnosed or undiagnosed hypertension among Chinese and Korean immigrants.

Our main findings pertain to those with undiagnosed hypertension. Regression analysis revealed that lack of health insurance was the most salient factor contributing to undiagnosed hypertension among Chinese and Korean immigrants, increasing risk of undiagnosed hypertension by 4.29 times, adjusting for all else. Other studies have similarly found that access to health insurance is associated with lower likelihood of undiagnosed hypertension $[45,50]$. A recent study by Huguet et al. (2021) found that rates of undiagnosed hypertension decreased with Medicaid expansion under the Affordable Care Act (ACA) [44, 45, 50]. However, the study also found that those of Hispanic ethnicity (who are more likely than non-Hispanic people to be foreign-born and have immigration-related barriers to healthcare) had longer time to hypertension diagnosis and treatment, and they were more likely to remain uninsured post-ACA compared to their non-Hispanic counterparts. Although the Huguet et al. (2021) study did not examine Asians separately from other race groups, we can conjecture that Asians experience similar immigration-related barriers to accessing insurance and healthcare as Hispanics, which affects rates of undiagnosed hypertension for both groups despite the passage of ACA $[44,51]$. Therefore, our analysis and other research suggests that increasing health insurance among Asian immigrants in the U.S. will help lower the rates of undiagnosed hypertension, but barriers likely still exist to gaining health insurance for many.

Given our finding that having no health insurance was strongly associated with having undiagnosed hypertension, 
we explored which sociodemographic characteristics were associated with health insurance status. Our study found that people with Medicare/Medicaid more likely to be older, Korean, have lower socioeconomic status, have poor English speaking proficiency, and to have immigrated at older ages compared to people with private health insurance. After adjustment for other variables, the strongest predictors of having Medicare/Medicaid were older age, male gender, being Korean, and having lower socioeconomic status. Overall patterns were similar for those without any health insurance. People with no insurance were more likely to be older, have lower education, have lower income, be working part time or not be working, have lower English-speaking proficiency, and have older age of immigration compared to people with private health insurance. Gender and Asian subgroup were not associated with having no insurance compared to having private insurance on our analysis. In regression analyses, the strongest predictors of having no health insurance were lower income and not currently working. This begs the question of what differentiates those who have Medicare/Medicaid versus those who have no health insurance? In our study, the two health insurance status groups had similar socioeconomic status and acculturation levels. It is possible that other factors not captured in this study, such as legal status and occupational barriers, determined which Asian American immigrants fell into the uninsured group.

One previous study examining insurance status found that Chinese and Korean subgroups had lower rates of health insurance coverage compared to Non-Hispanic white, Filipino, and Japanese groups [52]. They found that those with lower income had higher likelihood of being uninsured [52]. In addition, Chinese and Korean immigrants were more likely to be uninsured compared to U.S.-born Asian Americans, indicating potential immigration-related barriers to accessing health insurance [52]. Other research on insurance status among Asian American immigrants found that being uninsured was associated with Korean subgroup (compared to Chinese and other Asian subgroups), male gender, being unemployed or self-employed, low English proficiency, and having recently immigrated [53, 54]. Although Asian Americans are often thought of as financially well-off on average, socioeconomic status varies greatly [55]. Greater attention should be paid to those who have lower income and who may not qualify for benefits either because they do not meet the extremely low U.S. poverty thresholds, and/or because immigration status or occupational barriers prevent them from being able to access health insurance.

\section{Limitations}

The study has several limitations. First, this study is crosssectional, so we cannot determine causality. Even so, it is theoretically more likely that the lack of health insurance leads to undiagnosed hypertension than it is for undiagnosed hypertension to cause lack of health insurance in this study. Second, data is from a non-probability sample from doctor's clinics, so most people have some access to health care in this study. Nevertheless, about one fifth of the sample lacked health insurance and relatively high percentage had undiagnosed hypertension. Therefore, our study may underestimate the associations between lack of health insurance and undiagnosed hypertension in the population of people who do not seek care at physicians' clinics. Third, the study only included Chinese and Korean American immigrants, not other Asian subgroups. Other studies should examine undiagnosed hypertension in other Asian subgroups, as Asian Americans are quite diverse in their health outcomes and social determinants of health. Despite these limitations, our study is one of very few to examine sociodemographic factors associated with diagnosed and undiagnosed hypertension determined using both objectively measured blood pressure as well as selfreported diagnosis among Chinese and Korean immigrants.

\section{Conclusion}

Undiagnosed hypertension is a serious problem, which may lead to severe cardiovascular disease outcomes such as stroke or myocardial infarction $[4,56]$. As Chinese and Korean Americans experience disparities in hypertension and related health outcomes, it is important to increase the diagnosis and treatment of hypertension to prevent future mortality, morbidity, and disability in these populations. Although previous studies have suggested that more acculturated Korean and Chinese immigrants may have lower risk of undiagnosed hypertension [57], this appears not to be the case in our study. Instead, lack of health insurance among Asian immigrants was the main driver of undiagnosed hypertension. This points to the fact that barriers for Asian immigrants accessing health insurance may be the main explanation for why foreign-born Asian Americans are more likely to have undiagnosed hypertension compared to their U.S.-born counterparts, rather than cultural explanations.

Our study suggests that improving access to health insurance will likely improve diagnosis and treatment of hypertension among vulnerable Chinese and Korean American immigrants. We advocate for reforms that will improve access to health insurance among Asian American immigrants, especially those with lower socioeconomic status. These reforms may include decreasing legal barriers for immigrants to access public health insurance options, such as the current five-year bar that restricts lawfully present immigrants from accessing federal public benefits $[26,58$, 59]. States can also act to increase health insurance access for immigrant groups. Furthermore, more efforts can be made to help immigrants navigate the U.S. health insurance 
system. This may include providing easy-to-access health insurance related information in Asian languages and supporting multilingual health navigators who can provide help to Asian communities for accessing health care [60, 61]. Increasing access to health insurance among Asian American immigrants will likely improve health equity and decrease economic costs associated with undiagnosed and untreated hypertension.

Acknowledgements This research was supported by the National Institute on Minority Health and Health Disparities (NIMHD) of the National Institutes of Health under Award Number R01MD012778. The content is solely the responsibility of the authors and does not necessarily represent the official views of the National Institutes of Health.

Author Contributions This study was conceptualized by BNM. Writing of the original draft and data analysis were performed by BNM and CV. Supervision, funding acquisition, data collection and management, and resources were provided by SL. All authors contributed to reviewing and editing, and all have approved the final manuscript.

Data Availability Individuals who are interested in accessing data from this manuscript should contact the corresponding author, and de-identified data may be shared in compliance with NIH regulations.

Code Availability Statistical code were completed in Stata version 16 and are available upon request.

\section{Declarations}

Conflict of interest Except the funding source, the authors have no additional conflicts of interest or competing interests to declare. The ideas expressed in this manuscript are those of the authors and are not necessarily those of the institutions or funders.

Ethical Approval This study received ethics approval from the Institutional Review Boards of the University of Maryland and University of California, Irvine.

Consent to Participate All respondents completed informed consent prior to participating in the study.

\section{References}

1. Division for Heart Disease and Stroke Prevention. (2021). Undiagnosed hypertension. In: Million Hearts. Centers for Disease Control and Prevention, Atlanta, GA. Retrieved September 24, 2021 from https://millionhearts.hhs.gov/tools-protocols/undia gnosed-hypertension.html

2. Wall, H. K., Hannan, J. A., \& Wright, J. S. (2014). Patients with undiagnosed hypertension: Hiding in plain sight. JAMA, 312(19), 1973-1974. https://doi.org/10.1001/jama.2014.15388

3. National Heart Lung and Blood Institute. (2021). High blood pressure. National Institutes of Health, Bethesda, MD. Retrieved October 8, 2021 from https://www.nhlbi.nih.gov/health-topics/ high-blood-pressure

4. Zallman, L., Himmelstein, D. H., Woolhandler, S., et al. (2013). Undiagnosed and uncontrolled hypertension and hyperlipidemia among immigrants in the US. Journal of Immigrant and Minority Health, 15(5), 858-865. https://doi.org/10.1007/ s10903-012-9695-2

5. Budiman, A., \& Ruiz, N. G. (2021). Key facts about Asian Americans, a diverse and growing population. Pew Research Center.

6. Kim, E. J., Kim, T., Conigliaro, J., Liebschutz, J. M., PaascheOrlow, M. K., \& Hanchate, A. D. (2018). Racial and ethnic disparities in diagnosis of chronic medical conditions in the USA. Journal of General Internal Medicine, 33(7), 1116-1123. https:// doi.org/10.1007/s11606-018-4471-1

7. Jung, M. Y., Lee, S., Thomas, S. B., \& Juon, H.-S. (2019). Hypertension prevalence, treatment, and related behaviors among Asian Americans: An examination by method of measurement and disaggregated subgroups. Journal of Racial and Ethnic Health Disparities., 6(3), 584-593.

8. Centers for Disease Control and Prevention. (2019). Health, United States, 2018. Table 26. National Center for Health Statistics.

9. Wong, R. J., Chou, C., Sinha, S. R., Kamal, A., \& Ahmed, A. (2014). Ethnic disparities in the association of body mass index with the risk of hypertension and diabetes. Journal of Community Health, 39(3), 437-445. https://doi.org/10.1007/ s10900-013-9792-8

10. Yi, S. S., Thorpe, L. E., Zanowiak, J. M., Trinh-Shevrin, C., \& Islam, N. S. (2016). Clinical characteristics and lifestyle behaviors in a population-based sample of Chinese and South Asian immigrants with hypertension. American Journal of Hypertension, 29(8), 941-947.

11. Fang, J., Zhang, Z., Ayala, C., Thompson-Paul, A. M., \& Loustalot, F. (2019). Cardiovascular health among non-hispanic Asian Americans: NHANES, 2011-2016. Journal of the American Heart Association, 8(13), e011324. https://doi.org/10.1161/ JAHA.118.011324

12. Fei, K., Rodriguez-Lopez, J. S., Ramos, M., et al. (2017). Racial and ethnic subgroup disparities in hypertension prevalence, New York City Health and Nutrition Examination Survey, 2013-2014. Preventing Chronic Disease, 14, 201. https://doi.org/10.5888/ pcd14.160478

13. Katz, E. G., Stevens, J., Truesdale, K. P., Cai, J., North, K. E., \& Steffen, L. M. (2013). Associations of body mass index with incident hypertension in American white, American black and Chinese Asian adults in early and middle adulthood: The Coronary Artery Risk Development in Young Adults (CARDIA) study, the Atherosclerosis Risk in Communities (ARIC) study and the People's Republic of China (PRC) study. Asia Pacific Journal of Clinical Nutrition, 22(4), 626-634. https://doi.org/10.6133/apjcn. 2013.22.4.12

14. Seok Lee, H., Park, Y.-M., Han, K., et al. (2020). Obesity-related hypertension: Findings from The Korea National Health and Nutrition Examination Survey 2008-2010. PLoS ONE, 15(4), e0230616. https://doi.org/10.1371/journal.pone.0230616

15. Jose, P. O., Frank, A. T. H., Kapphahn, K. I., et al. (2014). Cardiovascular disease mortality in Asian Americans. Journal of the American College of Cardiology, 64(23), 2486-2494. https://doi. org/10.1016/j.jacc.2014.08.048

16. Hastings, K. G., Jose, P. O., Kapphahn, K. I., et al. (2015). Leading causes of death among Asian American subgroups (20032011). PLoS ONE, 10(4), e0124341. https://doi.org/10.1371/journ al.pone. 0124341

17. Heron, M. (2019). Deaths: Leading causes for 2017. National Center for Health Statistics.

18. Heo, S., Kwon, S., Lee, Y.-M., Shin, J.-Y., \& Lee, D.-H. (2020). Comparison of Trends in blood pressure and the prevalence of obesity among Korean and American adolescents: A 12-years 
cross-sectional study. Journal of Preventive Medicine and Public Health, 53(1), 45-55. https://doi.org/10.3961/jpmph.19.198

19. Young, D. R., Fischer, H., Arterburn, D., et al. (2018). Associations of overweight/obesity and socioeconomic status with hypertension prevalence across racial and ethnic groups. Journal of Clinical Hypertension (Greenwich, Conn.), 20(3), 532-540. https://doi.org/10.1111/jch.13217

20. John, D. A., de Castro, A. B., Duran, B., \& Martin, D. P. (2013). Nativity and occupational class disparities in uninsurance and routine preventive care use among Asian Americans. Journal of Immigrant and Minority Health, 15(6), 1011-1022. https://doi. org/10.1007/s10903-013-9851-3

21. Kim, W., \& Keefe, R. H. (2010). Barriers to healthcare among Asian Americans. Social Work in Public Health, 25(3-4), 286295. https://doi.org/10.1080/19371910903240704

22. Pourat, N., Kagawa-Singer, M., Breen, N., \& Sripipatana, A. (2010). Access versus acculturation: Identifying modifiable factors to promote cancer screening among Asian American women. Medical Care, 48(12), 1088-1096.

23. Egan, B. M., Li, J., Small, J., Nietert, P. J., \& Sinopoli, A. (2014). The growing gap in hypertension control between insured and uninsured adults. Hypertension, 64(5), 997-1004. https://doi.org/ 10.1161/HYPERTENSIONAHA.114.04276

24. Kaushal, N., \& Kaestner, R. (2005). Welfare reform and health insurance of immigrants. Health Services Research, 40(3), 697722. https://doi.org/10.1111/j.1475-6773.2005.00381.x

25. HealthCare.gov. (2021). Coverage for lawfully present immigrants. In Immigrants. Department of Health and Human Services, Baltimore, MD. Retrieved October 8 2021, https://www. healthcare.gov/immigrants/lawfully-present-immigrants/

26. Morey, B. N. (2018). Mechanisms by which anti-immigrant stigma exacerbates racial/ethnic health disparities. American Journal of Public Health, 108(4), 460-463. https://doi.org/10.2105/AJPH. 2017.304266

27. Hagan, J., Rodriguez, N., Capps, R., \& Kabiri, N. (2003). The effects of recent welfare and immigration reforms on immigrants' access to health care. International Migration Review, 37(2), 444 463. https://doi.org/10.1111/j.1747-7379.2003.tb00144.x

28. Touw, S., McCormack, G., Himmelstein, D. U., Woolhandler, S., \& Zallman, L. (2021). Immigrant essential workers likely avoided medicaid and SNAP because of a change to the public charge rule. Health Affairs, 40(7), 1090-1098. https://doi.org/10.1377/hlthaff. 2021.00059

29. Kim, E. J., Kim, T., Paasche-Orlow, M. K., Rose, A. J., \& Hanchate, A. D. (2017). Disparities in Hypertension associated with limited english proficiency. Journal of General Internal Medicine, 32(6), 632-639. https://doi.org/10.1007/s11606-017-3999-9

30. Abraido-Lanza, A. F., Echeverria, S. E., \& Florez, K. R. (2016). Latino immigrants, acculturation, and health: Promising new directions in research. Annual Review of Public Health, 37, 219 236. https://doi.org/10.1146/annurev-publhealth-032315-021545

31. Lee, S., Nguyen, H. A., \& Tsui, J. (2011). Interview language: A proxy measure for acculturation among Asian Americans in a Population-Based Survey. Journal of Immigrant and Minority Health, 13(2), 244-252. https://doi.org/10.1007/s10903-009-9278-Z

32. Lee, S., Chen, L., Jung, M. Y., Baezconde-Garbanati, L., \& Juon, H.-S. (2014). Acculturation and cancer screening among Asian Americans: Role of health insurance and having a regular physician. Journal of Community Health, 39(2), 201-212.

33. Daskalopoulou, S. S., Rabi, D. M., Zarnke, K. B., et al. (2015). The 2015 Canadian hypertension education program recommendations for blood pressure measurement, diagnosis, assessment of risk, prevention, and treatment of hypertension. Canadian Journal of Cardiology, 31(5), 549-568. https://doi.org/10.1016/j.cjca. 2015.02.016
34. National High Blood Pressure Education Program. (2003). The Seventh Report of the Joint National Committee on prevention, detection, evaluation, and treatment of high blood pressure. National Heart, Lung, and Blood Institute.

35. Smart, J. F., \& Smart, D. W. (1995). Acculturative stress of hispanics: Loss and challenge. Journal of Counseling \& Development, 73(4), 390-396. https://doi.org/10.1002/j.1556-6676.1995. tb01770.x

36. Yakushko, O., Watson, M., \& Thompson, S. (2008). Stress and coping in the lives of recent immigrants and refugees: Considerations for counseling. International Journal for the Advancement of Counselling, 30(3), 167-178. https://doi.org/10.1007/ s10447-008-9054-0

37. Tummala-Narra, P., Alegria, M., \& Chen, C.-N. (2012). Perceived discrimination, acculturative stress, and depression among South Asians: Mixed findings (pp. 3-16). Educational Publishing Foundation.

38. Gee, G. C., Spencer, M., Chen, J., Yip, T., \& Takeuchi, D. T. (2007). The association between self-reported racial discrimination and 12-month DSM-IV mental disorders among Asian Americans nationwide. Social Science \& Medicine, 64(10), 1984-1996. https://doi.org/10.1016/j.socscimed.2007.02.013

39. Lueck, K., \& Wilson, M. (2010). Acculturative stress in Asian immigrants: The impact of social and linguistic factors. International Journal of Intercultural Relations, 34(1), 47-57. https://doi. org/10.1016/j.ijintrel.2009.10.004

40. Singh, S., McBride, K., \& Kak, V. (2015). Role of social support in examining acculturative stress and psychological distress among Asian American immigrants and three sub-groups: Results from NLAAS. Journal of Immigrant and Minority Health, 17(6), 1597-1606. https://doi.org/10.1007/s10903-015-0213-1

41. StataCorp L. (2019). Stata statistical software: Release 16. StataCorp L.

42. Du, Y., Shih, M., Lightstone, A. S., \& Baldwin, S. (2017). Hypertension among Asians in Los Angeles County: Findings from a multiyear survey. Preventive Medicine Reports, 6, 302-306. https://doi.org/10.1016/j.pmedr.2017.03.009

43. Kim, G., Chiriboga, D. A., Jang, Y., Lee, S., Huang, C.-H., \& Parmelee, P. (2010). Health status of older Asian Americans in California. Journal of the American Geriatrics Society, 58(10), 2003-2008. https://doi.org/10.1111/j.1532-5415.2010.03034.x

44. Huguet, N., Larson, A., Angier, H., et al. (2021). Rates of undiagnosed hypertension and diagnosed hypertension without antihypertensive medication following the affordable care act. American Journal of Hypertension, 34(9), 989-998. https://doi.org/10. 1093/ajh/hpab069

45. Paulose-Ram, R., Gu, Q., \& Kit, B. (2017). Characteristics of U.S. adults with hypertension who are unaware of their hypertension, 2011-2014. NCHS Data Brief, 278, 1-8.

46. Đoàn, L. N., Takata, Y., Hooker, K., Mendez-Luck, C., \& Irvin, V. L. (2021). Trends in cardiovascular disease by Asian American, Native Hawaiian, and Pacific Islander ethnicity, medicare health outcomes survey 2011-2015. The Journals of Gerontology: Series A. https://doi.org/10.1093/gerona/glab262

47. Lu, X., Juon, H.-S., He, X., Dallal, C. M., Wang, M. Q., \& Lee, S. (2019). The association between perceived stress and hypertension among Asian Americans: Does social support and social network make a difference? Journal of Community Health, 44(3), 451-462. https://doi.org/10.1007/s10900-018-00612-7

48. Abu-Saad, K., Chetrit, A., Eilat-Adar, S., et al. (2014). Blood pressure level and hypertension awareness and control differ by marital status, sex, and ethnicity: A population-based study. American Journal of Hypertension, 27(12), 1511-1520. https://doi.org/10. 1093/ajh/hpu081

49. Ramezankhani, A., Azizi, F., \& Hadaegh, F. (2019). Associations of marital status with diabetes, hypertension, cardiovascular 
disease and all-cause mortality: A long term follow-up study. PLoS ONE, 14(4), e0215593. https://doi.org/10.1371/journal. pone. 0215593

50. Meador, M., Lewis, J. H., Bay, R. C., Wall, H. K., \& Jackson, C. (2020). Who are the undiagnosed? Disparities in hypertension diagnoses in vulnerable populations. Family \& Community Health, 43(1), 35-45. https://doi.org/10.1097/FCH.0000000000 000242

51. Artiga, S., Hill, L., Orgera, K., \& Damico, A. (2021). Health coverage by race and ethnicity, 2010-2019. Kaiser Family Foundation.

52. Wang, N., Ozodiegwu, I., Gong, S., Wang, K., Xie, X. (2019). Multivariate analyses of social-behavioral factors with health insurance coverage among Asian Americans in California.

53. Tan, C., Wyatt, L. C., Kranick, J. A., Kwon, S. C., \& Oyebode, O. (2018). Factors associated with health insurance status in an Asian American population in New York City: Analysis of a communitybased survey. Journal of Racial and Ethnic Health Disparities, 5(6), 1354-1364. https://doi.org/10.1007/s40615-018-0485-y

54. Nguyen, D., Choi, S., \& Park, S. Y. (2015). The moderating effects of ethnicity and employment type on insurance coverage: Four Asian subgroups in California. Journal of Applied Gerontology, 34(7), 858-878. https://doi.org/10.1177/0733464813481849

55. Kochhar, R., \& Cilluffo, A. (2018). Income inequality in the U.S. is rising most rapidly among Asians. Pew Research Center.

56. Centers for Disease Control and Prevention. (2021). High Blood Pressure. Retrieved October 10, 2021 from https://www.cdc.gov/ bloodpressure/facts.htm
57. Tsuchiya, K., \& Demmer, R. T. (2021). Citizenship status and prevalence of diagnosed and undiagnosed hypertension and diabetes among adults in the U.S., 2011-2016. Diabetes Care, 44(3), e38-e39. https://doi.org/10.2337/dc20-2453

58. Van Hook, J. (2003). Welfare reform's chilling effects on noncitizens: Changes in noncitizen welfare recipiency or shifts in citizenship status? Social Science Quarterly, 84(3), 613-631. https://doi. org/10.1111/1540-6237.8403008

59. Jayapal, P. (2021). H.R.5227 - LIFT the BAR Act of 2021. Retrieved October 10, 2021 from https://www.congress.gov/bill/ 117th-congress/house-bill/5227/text?r=12\&s=1

60. Clough, J., Lee, S., \& Chae, D. H. (2013). Barriers to health care among Asian immigrants in the United States: A traditional review. Journal of Health Care for the Poor and Underserved, 24(1), 384-403.

61. Jang, Y., Yoon, J., \& Park, N. S. (2018). Source of health information and unmet healthcare needs in Asian Americans. Journal of Health Communication, 23(7), 652-660. https://doi.org/10.1080/ 10810730.2018.1500660

Publisher's Note Springer Nature remains neutral with regard to jurisdictional claims in published maps and institutional affiliations. 